\title{
INFLUÊNCIA DA INFESTAÇÃO DE OLIGONYCHUS ILICIS (MCGREGOR, 1917) (ACARI: TETRANYCHIDAE) SOBRE A TAXA DE FOTOSSÍNTESE POTENCIAL DE FOLHAS DE CAFEEIRO
}

\author{
R.A. Franco, P.R. Reis*, M.S. Zacarias, B.F. Altoé, J.P.R.A.D. Barbosa
}

EPAMIG-CTSM/EcoCentro, CP176, CEP37200-000, Lavras, MG, Brasil.E-mail: paulo.rebelles@epamig.ufla.br

\begin{abstract}
RESUMO
Oligonychus ilicis (McGregor, 1917) é um dos principais ácaros fitófagos do cafeeiro (Coffeaspp.), embora não esteja relacionado entre as pragas primárias. Esses ácaros vivem na superfície superior das folhas e, para se alimentar, perfuram as células da epiderme e do mesófilo e absorvem o conteúdo celular extravasado. Em consequência, as folhas perdem o brilho natural e tornam-se bronzeadas. O objetivo deste trabalho foi quantificar a taxa de fotossíntese de folhas de cafeeiro apresentando diferentes níveis de infestação de $O$. ilicis. O estudo foi realizado em plantas de cafeeiro (Coffea arabica L., cultivar Catuaí) envasadas e com três anos de idade, mantidas em casa de vegetação. Foram realizadas infestações em cinco diferentes níveis (0, 15, 30, 60 e 120 fêmeas adultas do ácaro/folha), com ácaros provenientes da criação de manutenção, em folhas do terceiro par, a partir do ápice e totalmente expandidas, localizadas em ramos do terço médio da planta, com cinco repetições. A medição da fotossíntese potencial foi realizada por meio do oxigênio fotossintético produzido, utilizando-se de um monitor de oxigênio com eletrodo tipo Clark acoplado a uma caixa de controle de fluxo elétrico CB1. As avaliações foram realizadas 7 e 21 dias após a infestação com os ácaros, e os dados obtidos foram submetidos a uma análise de regressão. Houve correlação negativa entre os diferentes níveis de infestação e a fotossíntese potencial, sendo que, nos níveis 15, 30, 60 e 120 ácaros/folha, as taxas de fotossíntese foram reduzidas, em relação ao tratamento-testemunha, em 37,$2 ; 38,7 ; 46,0$ e 50,1\%, respectivamente.
\end{abstract}

PALAVRAS-CHAVE: Mbnitor de oxigênio, Coffea arabica, ácaro-vermelho-do-cafeeiro, bronzeamento.

\begin{abstract}
INFLUENCE OF OLIGONYCHUS ILICIS (MCGREGOR, 1917) (ACARI: TETRANYCHIDAE) INFESTATION ON THE POTENTIAL PHOTOSYNTHESIS RATE OF COFFEE-PLANT LEAVES. Oligonychus ilicis (McGregor, 1917), is one of the main phytophagous mites of the coffee plant (Coffea spp.), although it is not reported among the primary pests. They live on the upper surface of the leaves, puncturing the epidermis and mesophyll cells to absorb and feed on the extravasated cellular content. In consequence, the leaves lose their natural shine and become tan. The objective of this work was to quantify the photosynthetic rate of coffee-plant leaves presenting different infestation levels of O. ilicis. The study was carried out in potted three-year-old coffee plants (Coffea arabica L., Catuaí cultivar), kept in a greenhouse. Infestations were accomplished at five different levels $(0,15,30,60$ and 120 adult mite females/leaf), with mites coming from a stock rearing, on leaves of the third pair starting from the apex and totally expanded, located in branches from the middle third of the plant, with five repetitions. The potential photosynthesis was measured through the photosynthetic oxygen produced, using an oxygen monitor with a Clark type electrode coupled to a CB1 electric flow control box. The evaluations were made 7 and 21 days after the infestation with the mites, and the data obtained were submitted to regression analysis. There was a negative correlation between levels of infestation and potential photosynthesis, whereas at levels 15, 30, 60 and 120 mites/leaf, the photosynthetic rates were reduced in relation to the control treatment, in $37.2,38.7 ; 46.0$ and $50.1 \%$ respectively.
\end{abstract}

KEY WORDS: Oxygen monitoring, Coffea arabica, coffee red spider mite, leaf tanning.

*Pesquisador do CNPq. 


\section{INTRODUÇÃO}

Dentre os organismos que atacam o cafeeiro (Coffea spp.), destacam-se algumas espécies de ácaros que podem causar redução na produção e na qualidade do café. O ácaro Oligonychus ilicis (McGregor, 1917) (Acari: Tetranychidae), também conhecido como ácaro-vermelho-do-cafeeiro, é um dos principais ácaros fitófagos desta cultura. Embora não seja considerado como praga-chave, já foi referido como a segunda praga em importância para o cafeeiro Conillon, Coffea canephora Pierre \& Froehner, no Estado do Espírito Santo (IBC, 1985).

No Brasil, sua primeira referência atacando cafeeiro Arábica, Coffea arabica L., foi no Estado de São Paulo em 1950, embora sendo referido como outra espécie Paratetranychus ununguis Jacobi, 1905, juntamente com Brevipalpusphoenicis (Geijskes, 1939) (Acari: Tenuipalpidae) (AMARAL, 1951; A InFESTAÇÃo, 1951). A principal cultura atacada no Brasil por O. ilicis é a do cafeeiro (Moraes, 1992; Moraes; FlechtMAnN, 2008).

Esses ácaros vivem na face superior das folhas que, quando atacadas, apresentam-se recobertas por uma delicada teia, tecida pelos próprios ácaros, onde aderem detritos, poeira e suas exúvias, provenientes do processo de ecdise após os estádios quiescentes, dando às folhas um aspecto de sujeira. Para se alimentar, perfuram células da epiderme e do mesófilo e absorvem o conteúdo celular extravasado (MORAEs; FleCHTMANN, 2008). Em consequência, as folhas perdem o brilho natural, tornam-se bronzeadas, havendo redução da área foliar de fotossíntese. $\mathrm{O}$ ataque ocorre geralmente em reboleiras porém, se as condições forem favoráveis aoácaro e o controle não for feito no início da infestação, poderá atingir toda a lavoura. Períodos de seca, com estiagem prolongada, são condições propícias à proliferação do ácaro, podendo causar desfolha das plantas e provocar atraso no desenvolvimento de plantas jovens (REIS, 2005; REIS; SouZA, 1986).

O controle químico ainda é o método mais utilizado no manejo das pragas e doenças do cafeeiro. No entanto, o uso de certos defensivos para controle de insetos e doenças fúngicas pode causar considerável aumento populacional do ácaro-vermelho, em função da destruição de inimigos naturais ou do estímulo à oviposição (D' ANTONIO et al., 1980; D' ANTONIOet al., 1981; Ferreira et al., 1980; Oliveira, 1999; Oliveira, 2000; PAulini et al., 1975; PAulini et al., 1980; Reis, 2004; ReIs, 2005; ReIs et al., 1974; ReIs; TeOdoro, 2000). Comumente, entretanto, este ácaro encontra-se em equilíbrio, provavelmente devido ao clima e a presença de inimigos naturais na cultura do cafeeiro e nas vegetações adjacentes, como fragmentos florestais, quebra-ventos e cobertura vegetal do solo, de onde podem migrar para o cafeeiro.
Na literatura há registro de alguns trabalhos sobre efeito de ácaros na fotossíntese. Hall; Ferree (1975), em estudo com o ácaro Tetranychus urticae Koch, 1836 (Tetranychidae), determinaram sua influência sobre a fotossíntese em folhas de macieiras. Os resultados indicaram que nove dias após a infestação inicial com 15;30 e60ácaros/folha, houve redução na fotossíntese líquida de 26,30 e 43\%, respectivamente. Em folhas de pessegueiro [Prunus persica (L.) Batsch], Pérez-SAnTIAGO et al. (2004) determinaram o efeito do ácaro Eotetranychus lewisi (McGregor, 1943) (Tetranychidae) sobre a taxa de fotossíntese eclorofila com densidades iniciais de 0 (testemunha), 10-20;20-40 e 40-80ácaros. Durante o outono, foram feitas avaliações semanais e, ao final desta estação, observaram diminuições na taxa fotossintética de 23,9; 39,1 e 48,4\%, respectivamente, em relação à testemunha.

Em cafeeiro, é relatada a redução da área de fotossíntese em consequência do ataque do ácarovermelho, resultando em prejuízo ao desenvolvimento das plantas e produção do café (REIS;SouZA, 1986; Costa et al., 2003), tendo FAHL et al. (2006) constatado que há redução na fotossíntese em cafeeiro (C.arabica) como consequência da intensidade de bronzeamento causado pelo ataque de O. ilicis eSAN JuAN et al. (2007) demonstrado que $59,2 \%$ de folhas infestadas pelo ácaro podem provocar redução na produção de $65 \%$.

Dessa forma, o objetivo deste trabalho foi determinar quantitativamente a redução da atividade fotossintética em folhas de plantas de cafeeiro ( $C$. arabica) devido ao ataque de $\mathrm{O}$. ilicis em diferentes níveis de infestação.

\section{MATERIAL E MÉTODOS}

O estudo foi realizado em plantas de cafeeiro ( $C$. arabica, cultivar Catuaí) com três anos de idade, em vasos de barro de $20 \mathrm{~L}$, com o substrato constituído de sete partes de terra e três de esterco, mais adubo químico. As plantas foram mantidas em casa de vegetação, localizadas na fazenda experimental da Empresa de Pesquisa Agropecuária de Minas Gerais EPAMIG, Lavras, MG.

Criação de manutenção de $O$. ilicis: A criação de manutenção de $O$. ilicis foi realizada em folhas de cafeeiros (C. arabica) destacadas, isentas de aplicação de produtos fitossanitários, que serviram como arena ealimento aos ácaros. Esta criação foi iniciada a partir deácaros coletados em cafezal localizado próximo ao Departamento de Zootecnia da UniversidadeFederal de Lavras - UFLA, Lavras, MG, isentos de aplicação de defensivos.

Acriaçãofoimantida noLaboratóriode Acarologia doCentrodePesquisa em Manejo Ecológico dePragas e Doenças de Plantas - EcoCentro, da EPAMIG, no 
Campus da UFLA, a $25 \pm 2^{\circ} \mathrm{C}, 70 \pm 10 \%$ de UR e 14 horas de fotofase.

A metodologia de criação foi semelhante à utilizada por ReIs et al. (1997), na qual os ácaros foram confinados em arenas confeccionadas com folhas de cafeeiro destacadas e colocadas sobre uma esponja de $1 \mathrm{~cm}$ de espessura, que ocupava todo o fundo de uma placa de Petri de $20 \mathrm{~cm}$ de diâmetro por $2 \mathrm{~cm}$ de profundidade, sem tampa, colocando-se duas folhas por placa. As esponjas foram diariamente umedecidas com água destilada. As bordas das folhas foram recobertas por uma fina camada de algodão hidrófilo de aproximadamente $2 \mathrm{~cm}$ de largura, ficando também em contato com a esponja umedecida. Dessa forma, foi mantida a turgescência das folhas e os ácaros permaneceram nas arenas.

Critérios utilizados na avaliação dos experimentos: Para verificar o efeito do ataque do ácaro-vermelho na eficiência fotossintética do cafeeiro, foram realizadas infestações com este ácaro em folhas do terceiro par, a partir do ápice e totalmente expandidas, localizadas no terço médio do cafeeiro envasado.

O trabalho constou de duas avaliações, diferindo entre si apenas no período de avaliação da taxa de fotossíntese. A primeira avaliação foi realizada aos sete dias, e a segunda aos 21 dias após proceder-se à infestação com ácaros nas diferentes densidades. Cada avaliação constou de cinco repetições. As infestações iniciais foram em cinco diferentes níveis (0,15, 30, 60 e 120 fêmeas do ácaro adulto/folha) com ácaros provenientes da criação de manutenção em laboratório, sendo o nível zero correspondente ao tratamento-testemunha. Foram infestadas duas folhas por planta (uma para cada avaliação), passando-se cola entomológica (Bio Stick ${ }^{\circledR}$ ) em seu pecíolo para evitar a fuga dos ácaros.

Determinação da fotossíntese potencial: A taxade fotossíntese potencial foi medida por meio da produção deoxigêniofotossintéticoem discosfoliarescom 10 $\mathrm{cm}^{2}$ de área, utilizando-se do monitor de oxigênio com eletrodotipo Clarkacopladoa umacaixa decontrolede fluxo elétrico CB1 (Hansatech, Inglaterra), que amplifica as correntes vindas do eletrodo, seguindo a metodologia utilizada por DeLIEU; WALKES (1983).

As medidas de fotossíntese foram efetuadas em condições saturantes de $\mathrm{CO}_{2}$, pela da adição de $0,2 \mathrm{~mL}$ da solução $1 \mathrm{M}$ de $\mathrm{Na}_{2} \mathrm{CO}_{3} / \mathrm{NaHCO}_{3}$. Nestas condições, a fotorrespiração, assim como as limitações ao fluxo de $\mathrm{CO}_{2}$ para ocloroplasto, através dosestômatos, são praticamente eliminadas, sendo possível analisar o processo fotossintético sem tais interferências (DeLIEU; WALKer, 1981). Os discos foliares foram dispostos, dentro da câmara, sobre feltro umedecido para evitar a desidratação do tecido durante as avaliações. As determinações foram realizadas à temperatura de $35^{\circ} \mathrm{C}$.
Foi utilizado como fonte de luz um retroprojetor, que fornecia aproximadamente $1.500 \mu \mathrm{mol} . \mathrm{m}^{-2} \cdot \mathrm{s}^{-1} \mathrm{de}$ densidade de fluxo de fótons fotossinteticamente ativos (DFFFA), medida por um quantômetro acoplado a um pirômetro (modelo1600M; LI-COR, Lincoln.Neb). A determinação da fotossíntese potencial foi realizada em folhas sadias e em folhas com sintomas de bronzeamento após infestação pelo ácaro. Os dados obtidos foram submetidos à análise de regressão nãolinear, que, segundo BASTIAANS (1991), é a melhor opção para este tipo de avaliação, pois correlaciona melhor a intensidade de dano provocado por uma praga ou patógeno em plantas.

\section{RESULTADOS E DISCUSSÃO}

A média da fotossíntese potencial, no tratamentotestemunha, nas duas avaliações (7 e 21 dias), foi de $13,3 \mu \mathrm{molO}_{2} \cdot \mathrm{m}^{-2} \cdot \mathrm{s}^{-1}$, sendo menor do que o encontrado por DA MATTA et al. (1997), também para cafeeiro, que foi de $23,8 \mu \mathrm{molO}_{2} \cdot \mathrm{m}^{-2} \cdot \mathrm{s}^{-1}$, para a cultivar Catuaí. Uma possível explicação para tal diferença observada é que as plantas de cafeeiro, no caso deste trabalho, foram mantidas em casa de vegetação, já com alguns anos de uso, podendo ter havido alguma interferência (principalmente pela maior opacidade de seu material constituinte) na intensidade luminosa de seu interior. Souza (2001) demonstrou, em mudas de cafeeiro, que a variação nos níveis de radiação solar interfere na fotossíntese potencial, verificando que a cultivar Catuaí, quando exposta a $100 \%$ de radiação, apresenta fotossíntese potencial de $29,6 \mu \mathrm{mol} \mathrm{O}_{2} \cdot \mathrm{m}^{-2} \cdot \mathrm{s}^{-1} \mathrm{e}$, quando a $36 \%$ de radiação (considerando como sendo interior de casa de vegetação) apresentou 9,0 $\mu \mathrm{mol}$ $\mathrm{O}_{2} \cdot \mathrm{m}^{-2} \cdot \mathrm{s}^{-1}$, resultando, portanto, em um valor próximo ao obtido neste trabalho.

Tabela 1 - Porcentagem de redução da fotossíntese potencial em relação ao tratamento-testemunha, após 7 e 21 dias da infestação inicial.

\begin{tabular}{ccc}
\hline $\begin{array}{c}\text { Infestação inicial } \\
\text { (ácaros/folha) }\end{array}$ & Redução da fotossíntese potencial (\%) \\
\cline { 2 - 3 } & Após 7 dias & Após 21 dias \\
\hline 15 & 27,6 & 45,4 \\
30 & 39,4 & 38,1 \\
60 & 42,5 & 48,8 \\
120 & 50,7 & 49,6 \\
\hline
\end{tabular}

Foi possível correlacionar a infestação inicial de ácaros à fotossíntese potencial. Houve correlação 

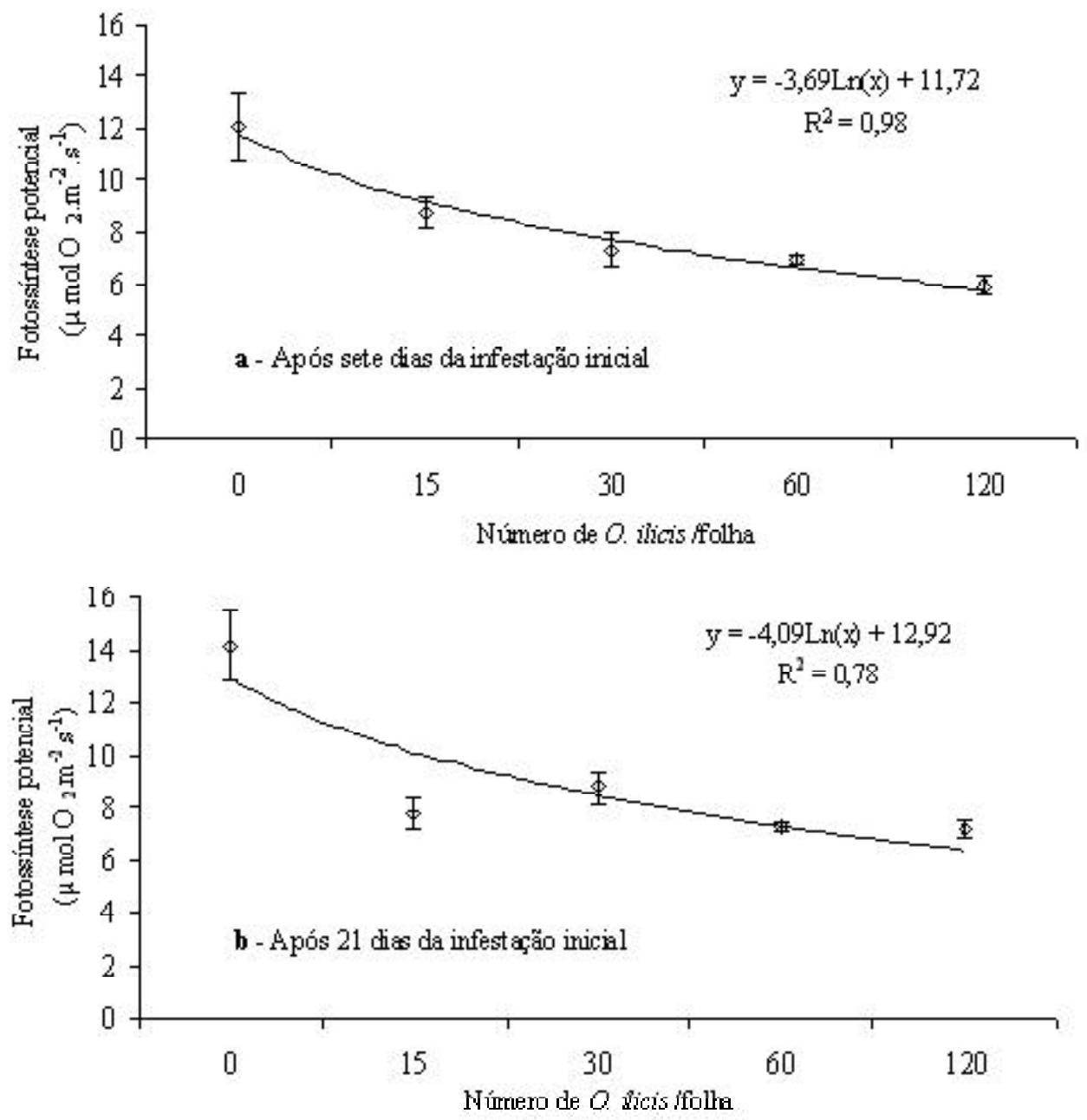

Fig. 1 - Efeito da densidade de ácaros O. ilicis por folha sobre a taxa de fotossíntese potencial, em função de diferentes níveis de infestação e do tempo decorrido após a infestação inicial.

negativa entre os diferentes níveis de infestação e a fotossíntese potencial, isto é, quanto maior o número deácaros na folha, menor foi a fotossíntese (Fig. 1a,b). Os danos causados nas folhas de cafeeiros por $O$. ilicis, nos diferentes níveis de infestação, reduziram as taxas de fotossíntese potencial em relação ao tratamento-testemunha, após sete e 21 dias da infestação inicial (Tabela 1).

Embora existam poucas informações na literatura sobre os danos causados por ácaros fitófagos na capacidade fotossintética de plantas, os resultados obtidos neste trabalho estão de acordo com os encontrados para outras espécies de ácaros da família Tetranychidae, à qual pertence O.ilicis. SegundoHALL; Ferree (1975), em estudo com o ácaro T. urticae, em folhas de macieira, nove dias após infestações com 15; 30 e 60 ácaros/folha, houve redução na fotossíntese líquida de 26, 30 e 43\%, respectivamente. PÉrEZ-SANTIAGO et al. (2004) também encontraram efeito negativo sobre a taxa de fotossíntese em plantas de pessegueiro, como consequência da infestação por E. lewisicom densidades iniciais de 10-20, 20-40 e 40-80 ácaros, e as reduções observadas na taxa fotossintética foram da ordem de 23,9;39,1 e 48,4\%, respectivamente, em relação à testemunha.

FAHL et al.(2006) também constataram que houve redução na fotossíntese de folhas de cafeeiro que apresentavam sintomas de bronzeamento, causado por $O$. ilicis, em relação a folhas aparentemente sadias.

Por esteácaro ocorrer mais na seca, que éépoca de maior déficit hídrico para a cultura, deve-se ter mais atenção para o seu controle nesse período, evitando com isso maiores danos, porém não deve ser esperada a ocorrência acentuada de folhas bronzeadas, pois, neste caso, o dano já foi estabelecido e é irreversível.

\section{CONCLUSÕES}

O ácaro O.ilicis causa danos nas folhas decafeeiro, reduzindo sua capacidade de fotossíntese em função 
do tempo de alimentação e intensidade de infestação, redução que pode chegar a mais de $50 \%$.

\section{AGRADECIMENTOS}

Os autores agradecem à professora Dra. Ângela Maria Soares, do Departamento de Biologia/Fisiologia Vegetal da UFLA, pela cessão dos equipamentos; ao Conselho Nacional de Desenvolvimento Científico e Tecnológico - CNPq, pelas bolsas concedidas, e ao Consórcio Brasileiro de Pesquisa e Desenvolvimento do Café-CBP\&D/Café, pelo suportefinanceiro e concessão de bolsa.

\section{REFERÊNCIAS}

\section{A INFESTAÇÃO DE ÁCAROS NOS CAFEZAIS. $O$ Biológico, São Paulo, v.17, n.7, p.130, 1951. [Notas e Inf.].}

AMARAL, J.F. do O ácaro dos cafezais. Boletim da Superintendência dos Serviços do Café, v.26, n.296, p.846848, 1951.

BASTIAANS, L. Ratio between virtual and visual lesion size as a measure to describe reduction in leaf photosynthesis of rice due to leaf blast. Phytopathology, v.81, n.6, p.611-615, 1991.

COSTA, J.N.M.; GAMA, F.C.; GARCIA, A.; TEIXEIRA, C.A.D.; SILVA, D.A. da; COSTA, R.S.C. da Efeitos da aplicação de piretróides e oxicloreto de cobre em Coffea canephora na dinâmica populacional de Oligonychus ilicis (Acari: Tetranychidae) em Rondônia. In: SIMPÓSIO DE PESQUISA DOS CAFÉS DO BRASIL, 3., 2003, Porto Seguro, BA. Resumos. Brasília: Embrapa Café, 2003. p.338-338.

D'ANTONIO, A.M.; PAULA, V. de; PAULINI, E.E.; GUIMARÃES, P.M. Efeito de piretróides usados no controle do bicho mineiro do cafeeiro, Perileucoptera coffeella (Guérin-Méneville, 1842), sobre os níveis populacionais do ácaro vermelho - Oligonychus (O.) ilicis (McGregor, 1919). In: CONGRESSO BRASILEIRO DE PESQUISAS CAFEEIRAS, 8., 1980, Campos do Jordão, SP. Resumos . Rio de Janeiro: IBC-GERCA, 1980. p.181-184.

D'ANTONIO, A.M.; PAULA, V. de; GUERRA NETO, E.G. Estudo do comportamento de diversos inseticidas piretróides sobre a população de ácaro vermelho do cafeeiro, Oligonychus (O.) ilicis (McGregor, 1919) e sobre bicho mineiro. In: CONGRESSO BRASILEIRO DE PESQUISAS CAFEEIRAS, 9., 1981, São Lourenço, MG. Resumos. Rio de Janeiro: IBC-GERCA, 1981. p.250-253.

DA MATTA, F.M.; MAESTRI, M.; MOSQUIM, P.R.; BARROS, R.S. Photosynthesis in coffee (Coffea arabica and $C$. canephora) as affected by winter and summer conditions. Plant Science, v.128, p.43-50, 1997.
DELIEU, T.; WALKER, D.A. Polarographic measurement of photosynthesis oxygen evolution by leaf discs. New Phytologist, v.89, p.165-178, 1981.

DELIEU, T.; WALKER, D.A. Simultaneous measurement of oxygen evolution and chlorophyll fluorescence from leaf pieces. Plant Physiology, v.73, p.534-541, 1983 .

FAHL, L.I.; QUIROZ-VOLTAN, R.B.; CARELLI, M.L.C.; SCHIAVINATO, M.A.; PRADO, A.K.S., SOUZA, J.C. Efeito do ácaro-vermelho no cafeeiro. In: CONGRESSO BRASILEIRO DE PESQUISAS CAFEEIRAS, 32., 2006, Poços de Caldas, MG. Resumos. Rio de Janeiro: MARASDR/PROCAFÉ, 2006. p.210-211.

FERREIRA, A.J.; PAULINI, A.E.; D'ANTONIO, A.M.; GUIMARÃES, P.M.; PAULA, V. de Misturas de piretróides sintéticos com acaricidas e inseticidas acaricidas com a finalidade de controle simultâneo de bicho mineiro Perileucoptera coffeella (Guér.-Mén., 1842) e ácaro vermelho Oligonychus ilicis (McGregor, 1919). In: CONGRESSO BRASILEIRO DE PESQUISAS CAFEEIRAS, 8., 1980, Campos do Jordão, SP. Resumos. Rio de Janeiro: IBC-GERCA, 1980. p. 25-29.

HALL, F.R.; FERREE, D.C. Influence of twospotted spider mite populations on photosynthesis of apple leaves. Journal of Economic Entomology, v.68, n.4, p.517$520,1975$.

INSTITUTO BRASILEIRO DO CAFÉ Cultivo do café conilon. Cultura do café no Brasil: manual de recomendações. Rio de Janeiro: IBC-GERCA, 1985. p.527-556.

MORAES, G.J. Perspectivas para o uso de predadores no controle de ácaros fitófagos no Brasil. Pesquisa Agropecuária Brasileira, v.27, S/N, p.263-270, 1992.

MORAES, G.J.; FLECHTMANN, C.H.W. Manual de acarologia: acarologia básica e ácaros de plantas cultivadas no Brasil. Ribeirão Preto: Holos, 2008. 288p.

OLIVEIRA, C.A.L. de Relação entre dosagens de deltametrina e o aumento populacional de Oligonychus ilicis (Acari: Tetranychidae) em mudas de cafeeiro. Ecossistema, v.24, p.116-118, 1999.

OLIVEIRA, C.A.L. de Efeito da aplicação de piretróides na cultura do cafeeiro sobre o ácaro Oligonychus ilicis (McGregor) (Acari: Tetranychidae) e seus predadores. Ecossistema, v.25, p.28-34, 2000.

PAULINI, A.E.; MIGUEL, A.E.; MANSK, Z. Efeito de fungicidas sobre o aumento da população do ácaro vermelho Oligonychus (O.) ilicis (McGregor, 1919) em cafeeiros. In: CONGRESSO BRASILEIRO DE PESQUISAS CAFEEIRAS, 3., 1975, Curitiba, PR. Resumos. Rio de Janeiro: IBC-GERCA, 1975. p.38-40. 
PAULINI, A.E.; D'ANTONIO, A.M.; MATIELLO, J.B. Efeito de inseticidas e acaricidas sobre a população de ácaro vermelho Oligonychus (O.) ilicis (McGregor, 1919). In: CONGRESSO BRASILEIRO DE PESQUISAS CAFEEIRAS, 8., 1980, Campos do Jordão, SP. Resumos. Rio de Janeiro: IBC-GERCA, 1980. p. 299-301.

PÉREZ-SANTIAGO, G.; OTERO-COLINA, G.; HERNÁNDEZ, V.A.G.; JIMÉNEZ. A.L.; GUZMAN, M.E.R.; HERNÁNDEZ, H.G. Tasa de fotosintesis y clorofila en duraznero (Prunus persica) a diferentes densidades de Eotetranychus lewisi (Acari: Tetranychidae). In: SEMINÁRIO CIENTIFICO INTERNACIONAL DE SANIDAD VEGETAL, 5., 2004, Havana, Cuba. Memorias/Proceedings. Havana, 2004. CD-ROM.

REIS, P.R.; SILVA, C.M. da; CARVALHO, J.G. de Fungicida cúprico atuando como fator de aumento da população do ácaro Oligonychus (O.) ilicis (McGregor, 1919) (Acari: Tetranychidae) em cafeeiro. Fitopatologia, v.9, n.2, p.67, 1974.

REIS, P.R.; SOUZA, J.C. de Pragas do cafeeiro. IN: RENA, A.B.; MALAVOLTA, E.; ROCHA, M.; YAMADA, T. (Ed.). Cultura do cafeeiro: fatores que afetam a produtividade. Piracicaba: POTAFÓS, 1986. p.323-378.

REIS, P.R.; ALVES, E.B.; SOUSA, E.O. Biologia do ácarovermelho do cafeeiro Oligonychus ilicis (McGregor, 1917). Ciência e Agrotecnologia, v.21, n.3, p.260-266, 1997.
REIS, P.R.; TEODORO, A.V. Efeito do oxicloreto de cobre sobre a reprodução do ácaro-vermelho do cafeeiro, Oligonychus ilicis (McGregor, 1917). Ciência e Agrotecnologia, v.24, n.2, p.347-352, 2000.

REIS, P.R. Ácaro-vermelho do cafeeiro: bioecologia, dano e manejo. Lavras: EPAMIG-CTSM, 2004. 4p. (Circular Técnica, 171).

REIS, P.R. Ácaro-vermelho. Cultivar, v.7, n.72, p.14-17, 2005.

SAN JUAN, R.C.C.; FIORELLI, J.H.; MATIELLO, J.B.; PAIVA, R.N.; REIS, R.P.; ANDRADE, R.J.; RAMOS, S.V. Quantificação do nível de dano pelo ataque do ácaro vermelho do cafeeiro no Sul de Minas. In: CONGRESSO BRASILEIRO DE PESQUISAS CAFEEIRAS, 33., 2007, Lavras, MG. Resumos. Varginha: MAPA/PROCAFÉ, 2007. p.72-73.

SOUZA, N.L. Comportamento fisiológico de cultivares de Coffea arabica L. submetidos a diferentes níveis de radiação solar. 2001. 41f. Dissertação (Mestrado) - Universidade Federal de Lavras, Lavras, 2001.

Recebido em 2/4/08

Aceito em 26/5/09 